NASA/TM-2007-215019

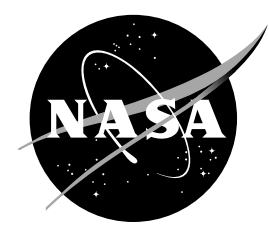

\title{
Determination of Turboprop Reduction Gearbox System Fatigue Life and Reliability
}

Erwin V. Zaretsky

Glenn Research Center, Cleveland, Ohio

David G. Lewicki

U.S. Army Research Laboratory, Glenn Research Center, Cleveland, Ohio

Michael Savage

The University of Akron, Akron, Ohio

Brian L. Vlcek

Georgia Southern University, Statesboro, Georgia 


\section{NASA STI Program . . . in Profile}

Since its founding, NASA has been dedicated to the advancement of aeronautics and space science. The NASA Scientific and Technical Information (STI) program plays a key part in helping NASA maintain this important role.

The NASA STI Program operates under the auspices of the Agency Chief Information Officer. It collects, organizes, provides for archiving, and disseminates NASA's STI. The NASA STI program provides access to the NASA Aeronautics and Space Database and its public interface, the NASA Technical Reports Server, thus providing one of the largest collections of aeronautical and space science STI in the world. Results are published in both non-NASA channels and by NASA in the NASA STI Report Series, which includes the following report types:

- TECHNICAL PUBLICATION. Reports of completed research or a major significant phase of research that present the results of NASA programs and include extensive data or theoretical analysis. Includes compilations of significant scientific and technical data and information deemed to be of continuing reference value. NASA counterpart of peer-reviewed formal professional papers but has less stringent limitations on manuscript length and extent of graphic presentations.

- TECHNICAL MEMORANDUM. Scientific and technical findings that are preliminary or of specialized interest, e.g., quick release reports, working papers, and bibliographies that contain minimal annotation. Does not contain extensive analysis.

- CONTRACTOR REPORT. Scientific and technical findings by NASA-sponsored contractors and grantees.
- CONFERENCE PUBLICATION. Collected papers from scientific and technical conferences, symposia, seminars, or other meetings sponsored or cosponsored by NASA.

- SPECIAL PUBLICATION. Scientific, technical, or historical information from NASA programs, projects, and missions, often concerned with subjects having substantial public interest.

- TECHNICAL TRANSLATION. Englishlanguage translations of foreign scientific and technical material pertinent to NASA's mission.

Specialized services also include creating custom thesauri, building customized databases, organizing and publishing research results.

For more information about the NASA STI program, see the following:

- Access the NASA STI program home page at http://www.sti.nasa.gov

- E-mail your question via the Internet to help@sti.nasa.gov

- Fax your question to the NASA STI Help Desk at 301-621-0134

- Telephone the NASA STI Help Desk at 301-621-0390

- Write to: NASA Center for AeroSpace Information (CASI) 7115 Standard Drive Hanover, MD 21076-1320 
NASA/TM-2007-215019

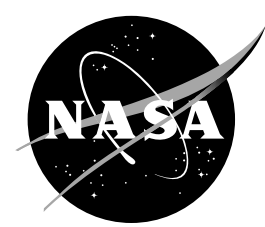

\section{Determination of Turboprop Reduction Gearbox System Fatigue Life and Reliability}

Erwin V. Zaretsky

Glenn Research Center, Cleveland, Ohio

David G. Lewicki

U.S. Army Research Laboratory, Glenn Research Center, Cleveland, Ohio

Michael Savage

The University of Akron, Akron, Ohio

Brian L. Vlcek

Georgia Southern University, Statesboro, Georgia

Prepared for the

World Tribology Congress III

sponsored by the International Tribology Council

Washington, DC, September 12-16, 2005

National Aeronautics and

Space Administration

Glenn Research Center

Cleveland, Ohio 44135 
This work was sponsored by the Fundamental Aeronautics Program at the NASA Glenn Research Center.

Level of Review: This material has been technically reviewed by technical management.

Available from

NASA Center for Aerospace Information 7115 Standard Drive

Hanover, MD 21076-1320
National Technical Information Service 5285 Port Royal Road Springfield, VA 22161

Available electronically at http://gltrs.grc.nasa.gov 


\title{
Determination of Turboprop Reduction Gearbox System Fatigue Life and Reliability
}

\author{
Erwin V. Zaretsky \\ National Aeronautics and Space Administration \\ Glenn Research Center \\ Cleveland, Ohio 44135 \\ David G. Lewicki \\ U.S. Army Research Laboratory \\ Glenn Research Center \\ Cleveland, Ohio 44135 \\ Michael Savage \\ The University of Akron \\ Akron, Ohio 44325 \\ Brian L. Vlcek \\ Georgia Southern University \\ Statesboro, Georgia 30460
}

\begin{abstract}
Two computational models to determine the fatigue life and reliability of a commercial turboprop gearbox are compared with each other and with field data. These models are (1) Monte Carlo simulation of randomly selected lives of individual bearings and gears comprising the system and (2) two-parameter Weibull distribution function for bearings and gears comprising the system using strict-series system reliability to combine the calculated individual component lives in the gearbox. The Monte Carlo simulation included the virtual testing of 744,450 gearboxes. Two sets of field data were obtained from 64 gearboxes that were first-run to removal for cause, were refurbished and placed back in service, and then were second-run until removal for cause. A series of equations were empirically developed from the Monte Carlo simulation to determine the statistical variation in predicted life and Weibull slope as a function of the number of gearboxes failed. The resultant $L_{10}$ life from the field data was 5,627 hr. From strict-series system reliability, the predicted $L_{10}$ life was $774 \mathrm{hr}$. From the Monte Carlo simulation, the median value for the $L_{10}$ gearbox lives equaled $757 \mathrm{hr}$. Half of the gearbox $L_{10}$ lives will be less than this value and the other half more. The resultant $L_{10}$ life of the second-run (refurbished) gearboxes was 1,334 hr. The apparent load-life exponent $p$ for the roller bearings is 5.2. Were the bearing lives to be recalculated with a load-life exponent $p$ equal to 5.2, the predicted $L_{10}$ life of the gearbox would be equal to the actual life obtained in the field. The component failure distribution of the gearbox from the Monte Carlo simulation was nearly identical to that using the strict-series system reliability analysis, proving the compatibility of these methods.
\end{abstract}

\section{Nomenclature}

$a_{1} \quad$ life factor for reliability

$a_{2} \quad$ life factor for material and processing

$a_{3} \quad$ life factor for operating conditions (lubrication and environment)

$B$ material life factor or constant for gear life

$C_{D} \quad$ dynamic load capacity, $\mathrm{N}$ (lbf) 
$C_{t} \quad$ basic load capacity of gear tooth, $\mathrm{N}(\mathrm{lbf})$

$c \quad$ stress-life exponent, $\mathrm{N}(\mathrm{lbf})$

$d \quad$ diameter of rolling element, $\mathrm{mm}$ (in.)

$e \quad$ Weibull slope

$f \quad$ face width of gear tooth, $m$ (in.)

$f_{c m} \quad$ bearing geometry and material coefficient

$h \quad$ exponent

$k$ number of load cycles of gear tooth per input shaft revolution

$L \quad$ life, number of stress cycles or $\mathrm{hr}$

$L_{n} \quad$ component $L_{10}$ life

$L_{\beta} \quad$ characteristic life or life at which 63.2 percent of population fails, number of stress cycles or hr

$L_{10} \quad$ 10-percent life or life at which 90 percent of a population survives, number of stress cycles or hr

$L_{50} \quad 50$-percent life or life at which 50 percent of a population survives, number of stress cycles or hr

$l \quad$ involute length, $\mathrm{m}$ (in.)

$m \quad$ Weibull modulus (same as Weibull slope $e$ )

$N \quad$ number of gear teeth on a gear

$n \quad$ number of components or gearboxes failed

$P_{e q} \quad$ equivalent radial load, $\mathrm{N}(\mathrm{lbf})$

$P_{t} \quad$ normal tooth load, N (lbf)

$p \quad$ load-life exponent

$r_{1} \quad$ pitch radius of pinion, $m$ (in.)

$r_{2} \quad$ pitch radius of gear, $m$ (in.)

$S \quad$ probability of survival, fraction or percent

$V \quad$ stressed volume, $\mathrm{m}^{3}$ (in. ${ }^{3}$ )

$X \quad$ fractional percent of components failed

$X_{n} \quad$ fractional percent of time at operational condition

$Z \quad$ number of rolling elements

$z \quad$ depth below surface, $m$ (in.)

$z_{o} \quad$ depth to orthogonal shearing stress, $\mathrm{m}$ (in.)

$\alpha \quad$ contact angle, deg

$\eta \quad$ number of stress cycles to failure

$\eta_{10_{t}} \quad$ life for single gear tooth at 90-percent probability of survival, millions of stress cycles

$\rho \quad$ curvature sum, $\mathrm{m}-1$ (in. -1$)=\left(1 / r_{1}+1 / r_{2}\right)(1 / \sin \varphi)$

$\tau_{o} \quad$ orthogonal shearing stress, GPa (ksi)

$\varphi \quad$ pressure angle, deg

Subscripts:

$B \quad$ bearing

$G \quad$ gear

$i \quad i^{\text {th }}$ component

sys system probability of survival or life

$t \quad$ gear tooth

$\beta \quad$ designation of characteristic life

1,2 bodies 1 or 2 ; load-life condition 1 , 2, etc. 


\section{Introduction}

Predicting and verifying the life of aircraft mechanical power trains, such as turboprop and helicopter main rotor gearboxes, is a complex task. Design requirements such as low weight and high power capacity need to be balanced with long life, high reliability, and low maintenance costs. The primary components of these power trains are combinations of rolling-element bearings, gears, and shafting. Accurate prediction of the lives of these components is necessary to establish reliability, predict replacement rates, set up maintenance and replacement schedules, and ascertain warranty limits.

The lives of these mechanical components are not deterministic but are probabilistic. A significant cause for power train removal and repair is contact (rolling-element) surface fatigue of the bearings and/or of the gears. Rolling-element fatigue is extremely variable but is statistically predictable depending on material (steel) type, processing, manufacturing, and operating conditions.

Rolling-element fatigue life analysis is based on the initiation or first evidence of fatigue spalling on a loaded, contacting surface of either a bearing or a gear. This spalling phenomenon is load cycle dependent. Generally, the spall begins in the region of maximum shear stresses, located below the contact surface, and propagates into a crack network. Failures other than that caused by classical rolling-element fatigue are considered avoidable if the component is properly designed, handled, installed, and not overloaded (ref. 1). However, under low elastohydrodynamic (EHD) lubricant film conditions, rollingelement fatigue can be surface or near-surface initiated with the spall propagating into the region of maximum shearing stresses.

In 1939, Weibull (refs. 2 to 4) developed a method and an equation for statistically evaluating the fracture strength of materials based upon small sample (population) sizes. This method can be and has been applied to analyze, determine, and predict the cumulative statistical distribution of fatigue failure or any other phenomenon or physical characteristic that manifests a statistical distribution.

Based on the work of Weibull (ref. 2) in 1939, Lundberg and Palmgren (ref. 5) in 1947 showed that the probability of survival $S$ could be expressed as a power function of the orthogonal shear stress $\tau_{o}$, life $\eta^{e}$, depth to the maximum orthogonal shear stress $z_{o}$, and stressed volume $V$. That is,

$$
\ln \frac{1}{S} \sim \tau_{o}{ }^{c} \frac{\eta^{e}}{z_{o}^{h}} V
$$

From equation (1), Lundberg and Palmgren (ref. 5) formulated the following relation for rollingelement bearings:

$$
L_{10}=\left[\frac{C_{D}}{P_{e q}}\right]^{p}
$$

where $C_{D}$ is the dynamic load capacity (the load that a bearing can carry for a life of 1 million inner-race revolutions with a 90-percent probability of survival ( $L_{10}$ life)), $P_{e q}$ is the equivalent radial load, and $p$ is the load life exponent.

Where the data base for gear life is limited, the data base for ball and roller bearings is significantly more extensive. A concern that arises from these data and the analysis is the variation between life calculations and the actual endurance characteristics of these components. Experience has shown that endurance tests of groups of identical bearings under identical conditions can produce a variation in $L_{10}$ life from group to group. If a number of apparently identical bearings are tested to fatigue at a specific load, there is a wide dispersion of life among these bearings. For a group of 30 or more bearings, the ratio of the longest to the shortest life may be 20 or more (ref. 1). For gears there is a similar variability. This variation can exceed reasonable engineering expectations. 
Between 1975 and 1981, Coy, Townsend, and Zaretsky (refs. 6 to 9) published a series of papers developing a methodology for calculating the life of spur and helical gears based upon the LundbergPalmgren theory and methodology for rolling-element bearings. These gear-life models utilize the Lundberg-Palmgren theory. Also developed from these models is a reliability model for planetary gear trains (refs. 10 to 15), which takes into account the individual reliabilities of the gearbox bearing and gears based upon classical rolling-element fatigue. The reliability of the gearbox system is treated as a strict-series probability combination of the reliabilities of the gearbox components in accordance with Lundberg-Palmgren theory (ref. 5). Each bearing and gear life was calculated and the results statistically combined to produce a system life for the total gearbox. Because of the different component Weibull slopes, a linear approximation was made to determine the system Weibull slope. The method was applied to a turboprop gearbox by Lewicki et al. (ref. 16).

Another method for determining the life of a system comprising multiple components is the Monte Carlo simulation (ref. 17). Vlcek et al. (ref. 18) determined the life of rolling-element bearings using this method and the two-parameter Weibull distribution function (ref. 4).

In view of the aforementioned, the following are objectives of the work reported herein: (a) to determine the variation in gearbox lives and distribution parameters as a function of sample size using a Monte Carlo simulation of randomly selected lives of individual bearings and gears comprising the system, (b) to determine the life of a gearbox based on a two-parameter Weibull distribution function for bearings and gears comprising the system using strict-series system reliability, and (c) to compare both methods with each other and with component and gearbox lives obtained from field data.

\section{Procedure and Analysis}

\section{Turboprop Gearbox}

The commercial turboprop gearbox used for this analysis (fig. 1) consists of two stages with a singlemesh spur reduction followed by a 5-planet planetary gearbox consisting of 11 rolling-element bearings and 9 spur gears (ref. 16). The first stage consists of the input pinion gear meshing with the main drive gear. The second stage is provided by the fixed-ring planetary driven by a floating sun gear as input with a five-planet carrier as output. At cruise conditions, the input pinion speed is constant at 13,820 rpm, producing a carrier output speed of 1,021 rpm. A list of the component parts of the gearbox is given in table 1.

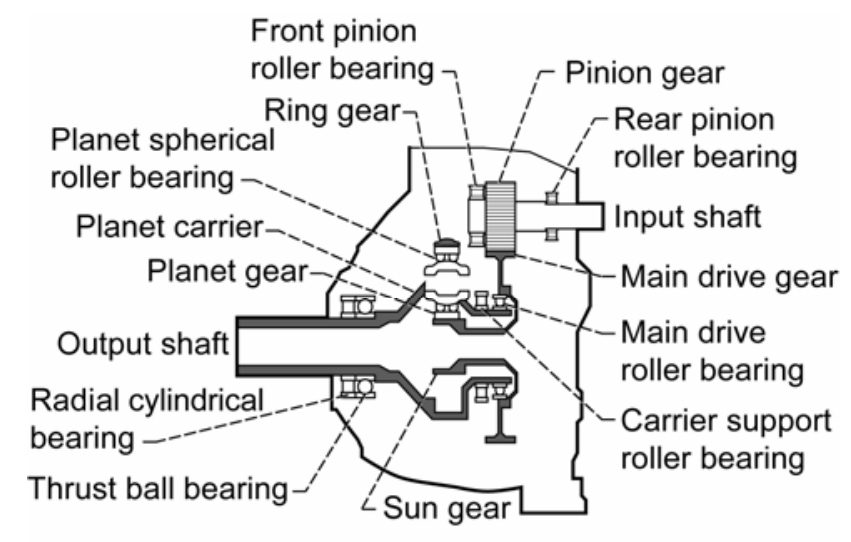

Figure 1.-Commercial turboprop gearbox. 
TABLE 1.-PREDICTED TURBOPROP GEARBOX COMPONENT LIVES FROM LUNDBERG-PALMGREN ANALYSIS WITH LIFE FACTORS AND STRICT-SERIES SYSTEM RELIABILITY

\begin{tabular}{|c|c|c|c|}
\hline \multirow{2}{*}{$\begin{array}{c}\text { Component description } \\
\text { (see fig. 1) }\end{array}$} & \multicolumn{2}{|c|}{ Predicted life, $\mathrm{hr}$} & \multirow{2}{*}{$\begin{array}{l}\text { Weibull } \\
\text { slope, } e\end{array}$} \\
\hline & $L_{10}$ & $L_{50}$ & \\
\hline \multicolumn{4}{|c|}{ Rolling-element bearings } \\
\hline \multicolumn{4}{|l|}{ Cylindrical roller bearings } \\
\hline Front pinion & 20,890 & 111,476 & 1.125 \\
\hline Rear pinion & 21,312 & 113,728 & 1 \\
\hline Main drive & 26,459 & 141,194 & \\
\hline Carrier support & 312,881 & $1,669,635$ & \\
\hline Propeller radial & 68,194 & 363,905 & $\downarrow$ \\
\hline Propeller thrust ball bearing & 33,065 & 180,484 & 1.11 \\
\hline Planet double-row spherical roller bearing set, 5 bearings & 844 & 4,503 & 1.125 \\
\hline Bearing system life & 774 & 4,132 & 1.125 \\
\hline \multicolumn{4}{|l|}{ Gears } \\
\hline Pinion & 53,477 & 131,552 & 2.5 \\
\hline Ring & $4,540,212$ & $11,168,760$ & \\
\hline Sun & 19,033 & 46,821 & \\
\hline Main drive & 108,148 & 266,040 & \\
\hline Planet gear set, 5 gears & 28,092 & 69,105 & $\downarrow$ \\
\hline Gear system life & 16,680 & 44,032 & 2.5 \\
\hline Gearbox life & 774 & 4,132 & 1.125 \\
\hline
\end{tabular}

A typical mission profile for this commercial gearbox is given in table 2, which presents the duration as a percentage and the propeller shaft power for each flight condition. This profile includes loads for (a) takeoff, (b) climb, (c) cruise, and (d) descent. The cruise segment of the profile consumes 68 percent of the flight time with a little less than half of the power required for the takeoff, which lasts for less than 3 percent of the flight time.

TABLE 2.-MISSION PROFILE OF COMMERCIAL TURBOPROP GEARBOX

\begin{tabular}{|l|c|c|}
\hline \multicolumn{1}{|c|}{$\begin{array}{c}\text { Mission } \\
\text { segment }\end{array}$} & $\begin{array}{c}\text { Percent time } \\
\text { of segment }\end{array}$ & $\begin{array}{c}\text { Propeller shaft power, } \\
\mathrm{kW}(\mathrm{hp})\end{array}$ \\
\hline Takeoff & 2.84 & $3,132(4,200)$ \\
Climb & 17.02 & $2,461(3,300)$ \\
Cruise & 68.08 & $1,516(2,033)$ \\
Descent & 12.06 & $945(1,267)$ \\
\hline Equivalent & 100.00 & $1,833(2,457)$ \\
\hline
\end{tabular}

The cause for removal can be assumed to be one or more bearings or gears that had fatigue or damage resulting in wear and/or vibration detected by magnetic chip detectors and/or vibration pickups. The gearbox is removed from service before secondary damage occurs and is inspected. After the failed part or parts are replaced, the gearbox is put back into service.

Individual failure occurrences are not predictable but are probabilistic. No two gearboxes run under the same conditions fail necessarily from the same cause and/or at the same time. At a given probability of survival, the life of the gearbox system will always be less than that of the lowest lived element in it.

Historical field data for 64 gearboxes were collected. The first part of these data covered the time from their field installation and first field operation to their removal for cause (failure) and refurbishment. The second part covered the time after refurbishment and placement back into field operation of 59 of the 64 gearboxes until their second removal for cause. 


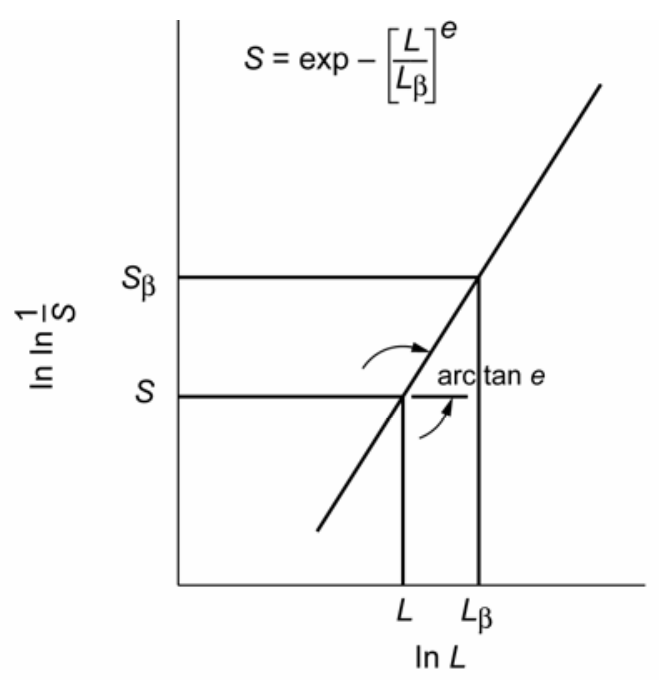

Figure 2.-Weibull plot where (Weibull) slope of tangent of line is $e$; probability of survival, $S_{\beta}$, is 36.8 percent at which $L=L_{\beta}$, or $L / L_{\beta}=1$.

\section{Weibull Analysis}

In 1939, Weibull (refs. 2 to 4) developed a method and an equation for statistically evaluating the fracture strength of materials. He also applied the method and equation to fatigue data based upon small sample (population) sizes, where the two-parameter expression relating life and probability of survival is

$$
\ln \ln \left(\frac{1}{S}\right)=e \ln \left(\frac{L}{L_{\beta}}\right) \quad \text { where } 0<L<\infty ; 0<S<1
$$

When plotting the $\ln \ln (1 / S)$ as the ordinate against the $\ln L$ as the abscissa, fatigue data are assumed to plot as a straight line (fig. 2). The ordinate $\ln \ln (1 / S)$ is graduated in statistical percent of components failed or removed for cause as a function of $\ln L$, the natural logarithm of the time or cycles to failure. The tangent of the line is designated th0e Weibull slope $e$, which is indicative of the shape of the cumulative distribution or the amount of scatter of the data. The method of using the Weibull distribution function for data analysis to determine component life and reliability was later developed and refined by L.G. Johnson (ref. 19). This method was used to analyze the data reported herein.

\section{Bearing Life Analysis}

Lundberg and Palmgren (refs. 5 and 20) extended the theoretical work of Weibull (refs. 2 to 4 ) and showed that the probability of survival $S$ could be expressed as a power function of shear stress $\tau$, number of stress cycles $\eta$, depth of maximum shear stress $z$, and stressed volume $V$ (see eq. (1)). By substituting the bearing geometry and the Hertzian contact stresses for a given load into equation (3), the bearing basic dynamic load capacity $C_{D}$ can be calculated (ref. 5). Lundberg and Palmgren related the $L_{10}$ life to the equivalent bearing load, load-life exponent, and the basic dynamic load capacity $C_{D}$ (eq. (2)).

For ball bearings, the generally accepted value for the exponent $p$ in equation (2) is 3 (ref. 5). Initially, for roller bearings the derived value for $p$ was 4 (ref. 5). However, in their subsequent work, Lundberg and Palmgren (ref. 20) recommended a value of $p$ of 10/3. The ANSI/ABMA and ISO standards (refs. 21 to 23) adopted a value of $p$ equal to 10/3 for roller bearings and a value of 3 for ball bearings. Bearing computer codes in use today use $p=3$ for ball bearings and $p=4$ for roller bearings. 
Formulas for the basic dynamic load ratings derived by Lundberg and Palmgren (refs. 5 and 20) are incorporated in the ANSI/AFBMA and ISO standards (refs. 21 and 23).

Equation (2) can be modified using life factors based on reliability $a_{1}$, materials and processing $a_{2}$, and operating conditions such as lubrication $a_{3}$ (ref. 1) where

$$
L=a_{1} a_{2} a_{3} L_{10}
$$

\section{Gear Life Analysis}

Between 1975 and 1981, Coy, Townsend, and Zaretsky (refs. 7 to 9) published a series of papers developing a methodology for calculating the life of spur and helical gears based upon the LundbergPalmgren theory and methodology for rolling-element bearings. Townsend, Coy, and Zaretsky (ref. 24) reported that for AISI 9310 spur gears, the Weibull slope $e$ is 2.5. Based on equation (1), for all gears except a planet gear, the gear life can be written as

$$
L_{10_{G}}=\frac{N^{-1 / e_{G}}\left(\eta_{10_{t}}\right)}{k}
$$

For a planet gear, the life is

$$
L_{10_{G}}=\frac{N^{-1 / e_{G}}\left(\eta_{10_{t 1}}^{-e_{G}}+\eta_{10_{t 2}}^{-e_{G}}\right)^{-1 / e_{G}}}{k}
$$

The $L_{10}$ life of a single gear tooth can be written as

$$
\eta_{10_{t}}=a_{2} a_{3}\left(\frac{C_{t}}{P_{t}}\right)^{p_{G}}
$$

where

$$
C_{t}=B f^{0.907} \rho^{-1.165} l^{-0.093}
$$

and

$$
\rho=\left(\frac{1}{r_{1}}+\frac{1}{r_{2}}\right) \frac{1}{\sin \varphi}
$$

and $\eta_{10_{t}}$ is the $L_{10}$ life in millions of stress cycles for one particular gear tooth. This number can be determined by using equation (7) where for bearings, $C_{t}$ is the basic load capacity of the gear tooth; $P_{t}$ is the normal tooth load; $p_{G}$ is the load-life exponent usually taken as 4.3 for gears based on experimental data for AISI 9310 steel; and $a_{2}$ and $a_{3}$ are life adjustment factors similar to those for rolling-element bearings. The value for $C_{t}$ can be determined by using equation (8), where $B$ is a material constant that is based on experimental data and is approximately equal to $1.39 \times 10^{8}$ when calculating $C_{t}$ in SI units (Newtons and meters) and is 21,800 in English units (pounds and inches) for AISI 9310 steel spur gears; $f$ is the tooth width; and $\rho$ is the curvature sum at the start of single-tooth contact.

The $L_{10_{G}}$ life of the gear (all teeth) in millions of input shaft revolutions at which 90 percent will survive can be determined from equation (5) or (6) where $N$ is the total number of teeth on the gear, $e_{G}$ is the 
Weibull slope for the gear and is assumed to be 2.5 (from (ref. 24)), and $k$ is the number of load (stress) cycles on a gear tooth per input shaft revolution.

For all gears except the planet gears, each tooth will see a load on only one side of its face for a given direction of input shaft rotation. However, each tooth on a planet gear will see contact on both sides of its face for a given direction of input shaft rotation. One side of its face will contact a tooth on the sun gear, and the other side of its face will contact a tooth on the ring gear. Equation (6) takes this into account, where $\eta_{10_{t 1}}$ is the $L_{10}$ life in millions of stress cycles of a planet tooth meshing with the sun gear, and $\eta_{10_{t 2}}$ is the $L_{10}$ life in millions of stress cycles of a planet tooth meshing with the ring gear.

\section{System Life Prediction}

The $L_{10}$ lives of the individual bearings and gears that make up a rotating machine are calculated for each condition of their operating profiles. For each component, the resulting lives from each of the operating conditions are combined using the linear damage (Palmgren-Langer-Miner) rule (refs. 25 to 27) where

$$
\frac{1}{L}=\frac{X_{1}}{L_{1}}+\frac{X_{2}}{L_{2}}+\cdots \frac{X_{n}}{L_{n}}
$$

The lives of each of the gearbox components are combined to determine the calculated system $L_{10}$ life using the two-parameter Weibull distribution function (eq. (3)) for the bearings and gears comprising the system and strict-series system reliability (ref. 10) as follows:

$$
\frac{1}{L_{s y s}^{e}}=\sum_{i=1}^{n} \frac{1}{L_{n}^{e}}=\left(\frac{1}{L_{1}^{e}}+\frac{1}{L_{2}^{e}}+\cdots \frac{1}{L_{n}^{e}}\right)
$$

The system shape parameter (Weibull slope) using strict-series reliability (eq. (11a)) where each component or combinations of multiple bearings and gears have different Weibull slopes (shape parameters) is not intuitively obvious. If at each time sequence the probability of survival of each component is multiplied together, the system reliability at that time and, hence, the probability of failure can be determined. When these values are plotted on Weibull paper, a Weibull slope (shape parameter) can be determined for the system life distribution using a least squares fit. When this is done, it is found that the system Weibull slope approximates that of the lowest lived component in the system. For the gearbox,

$$
\frac{1}{L_{s y s}^{e}}=\left(\frac{1}{L_{B_{1}}^{e_{B}}}+\frac{1}{L_{B_{2}}^{e_{B}}}+\ldots \frac{1}{L_{B_{n}}^{e_{B}}}\right)+\left(\frac{1}{L_{G_{1}}^{e_{G}}}+\frac{1}{L_{G_{2}}^{e_{G}}}+\ldots \frac{1}{L_{G_{n}}^{e_{G}}}\right)
$$

The lowest lived components in the gearbox are the roller bearings. As a result, the Weibull slope assumed for the planetary gear spherical roller bearings is assumed to be the Weibull slope $e$ of the entire gearbox system in eq. (11b). 


\section{Virtual Gearbox Testing}

It was assumed that the virtual gearbox was assembled from 12 virtual bins containing components listed in table 1. As in a realistic manufacturing process, each of the component parts of the gearbox is grouped in separate bins. Each of the virtual bins contains 1,000 of the respective components. According to the method of Johnson (ref. 19), each component part in the bin is assigned an order number $(1,2$, $3, \ldots 1,000)$ which is also the order in which they would fail. The life of each component at the probability of survival corresponding to the randomly selected rank can be determined using equation (3), knowing the survivability (from the order and ranking), characteristic life, and Weibull slope.

Using Monte Carlo techniques (ref. 18), various-sized groups or populations of gearboxes were randomly assembled from the virtual part bins. This group or population represented failure distributions of varying sizes; sizes of $2,3,4,5,6,8,10,12,14,16,18,20,22,24,26,28,30,35,40,45,50,58,72$, 100,200 , and 1000 were arbitrarily selected. At population sizes greater than 20 , the interval between population size was increased. Each random number generated within a population corresponded to an order number of a component in the virtual bin, with which an associated failure life was determined.

The life of the gearbox was that of the shortest lived component. All gearboxes in each set failed; there were no suspensions or censoring. As a result of the population sizes evaluated, a total of 744,450 virtual gearboxes was assembled and failed in this manner. From each population size $n$, a distribution of associated lives was thus determined.

Next, this distribution of fatigue lives was sequentially ranked and then ordered according to the method of Johnson (ref. 19). From the order number, a percent survivability was determined corresponding to each fatigue life. A curve fit of a Weibull plot with the independent variable of the natural logarithm of the life $(\ln L)$ and a dependent variable of the natural logarithm of the natural logarithm of the inverse of the probability of survival $(\ln \ln (1 / S))$ was created. A straight line was fitted to these $n$ data points using the method of least squares. The Weibull slope and the $L_{10}$ life of the gearbox systems were determined from the resultant line. For each value of $n$, the procedure was repeated 21 times to estimate variation between trials and to determine the maximum, minimum, and median values for each series of 21 trials. The 11th trial in ascending order of the 21 trials represents the median value. Ninety percent of the trials (19 trials) were bounded by the maximum and minimum $L_{10}$ life values. This entire process in turn was repeated 10 times to establish statistical variation between repetitions. Thus, the lives and slopes reported herein are averaged values from these 10 repetitions.

\section{Results and Discussion}

\section{Predicted Gearbox Life}

The commercial turboprop gearbox used for this analysis is shown in figure 1. Using equations (2) and (3) for bearings and equations (5) through (9) for gears and appropriate computer programs incorporating these equations, the lives of each of the bearings and gears making up the gearbox were predicted for each of their operating conditions. These lives are shown as the Weibull plots in figures 3(a) and (b), respectively.

The $L_{10}$ life of a single double-row spherical bearing is $3,529 \mathrm{hr}$. From equation (11a), the system $L_{10}$ life for the five-bearing planetary set is $774 \mathrm{hr}$. For all the bearings in the gearbox, the bearing system $L_{10}$ life is also predicted to be $774 \mathrm{hr}$.

Using equation (17a) for the individual gears, the gear system predicted $L_{10}$ life is $16,680 \mathrm{hr}$. Combining the bearing and gear lives to obtain a gearbox $L_{10}$ life, using equation (17b), the predicated $L_{10}$ life for the gearbox is $774 \mathrm{hr}$. The lives of the individual bearings, and more specifically, those of the planet double-row spherical bearings, determine the life of the gearbox in this example. The system lives of the bearings, gears, and gearbox are summarized in figure 3(c). 

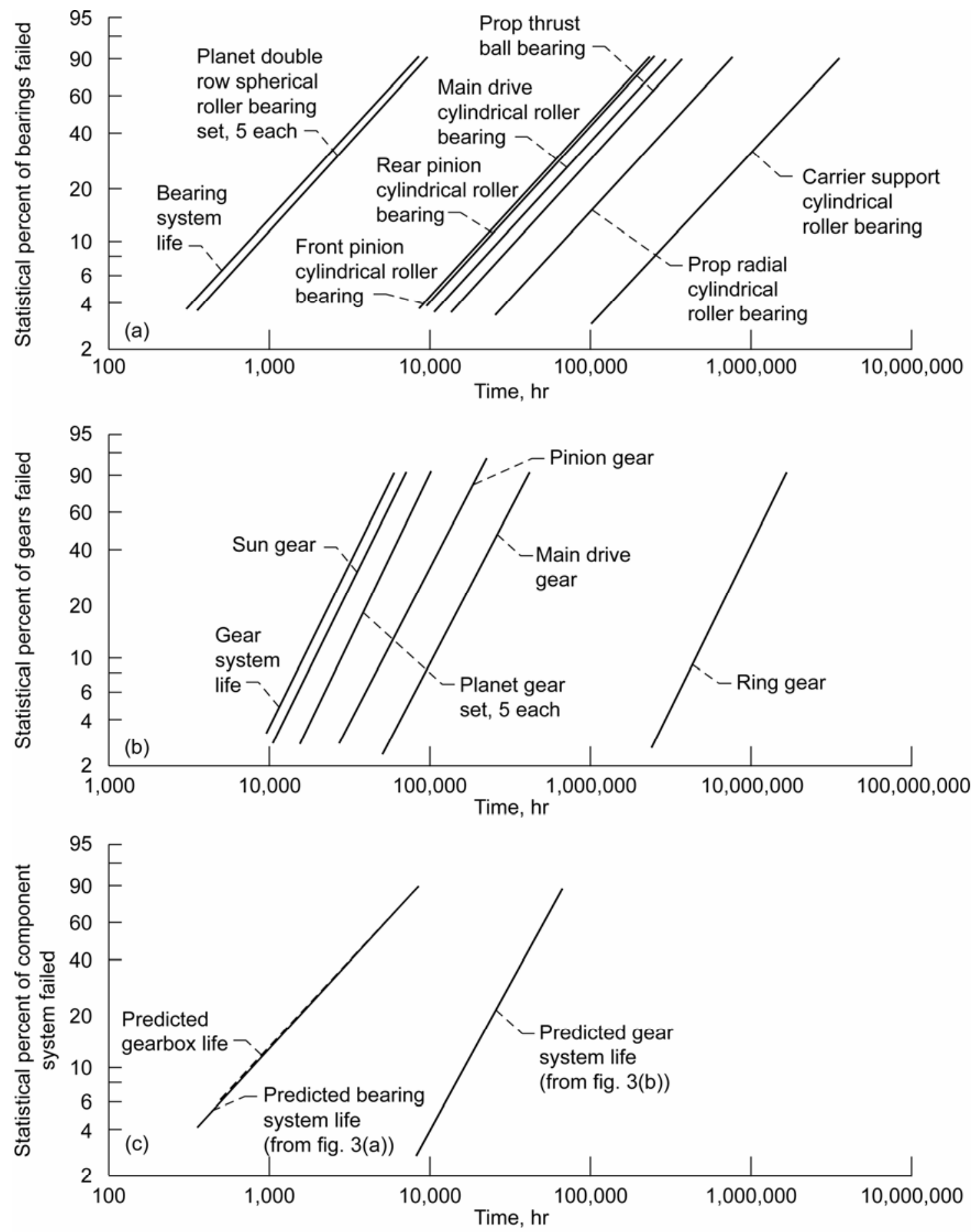

Figure 3.-Predicted lives for commercial turboprop gearbox and its respective bearing and gear components using Lundberg-Palmgren life theory. (a) Bearing component lives. (b) Gear component lives. (c) Gearbox life and component lives. 


\section{Virtual Gearbox Life}

For this study, gearboxes were randomly assembled by Monte Carlo (random) number generation (ref. 29) from 12 virtual bins. The method of Johnson (ref. 19) was used to determine the Weibull slope and lives. For each population size, the process to determine the virtual gearbox lives was repeated 21 times, from which the maximum and minimum lives and slopes could be determined at each population size. In turn, the process was repeated 10 times to establish the statistical variation, and the virtual lives and slopes are reported as averages of the 10 repetitions. The maximum and minimum lives of 21 trials were averaged for 10 repetitions and plotted as a function of population size in figure 4(a). The median values for the $L_{10}$ gearbox lives equal $757 \mathrm{hr}$ and reasonably correlate with the predicted value of $774 \mathrm{hr}$ from the Lundberg-Palmgren method. Half the gearbox $L_{10}$ lives, however, will be less than this value and the other half greater.
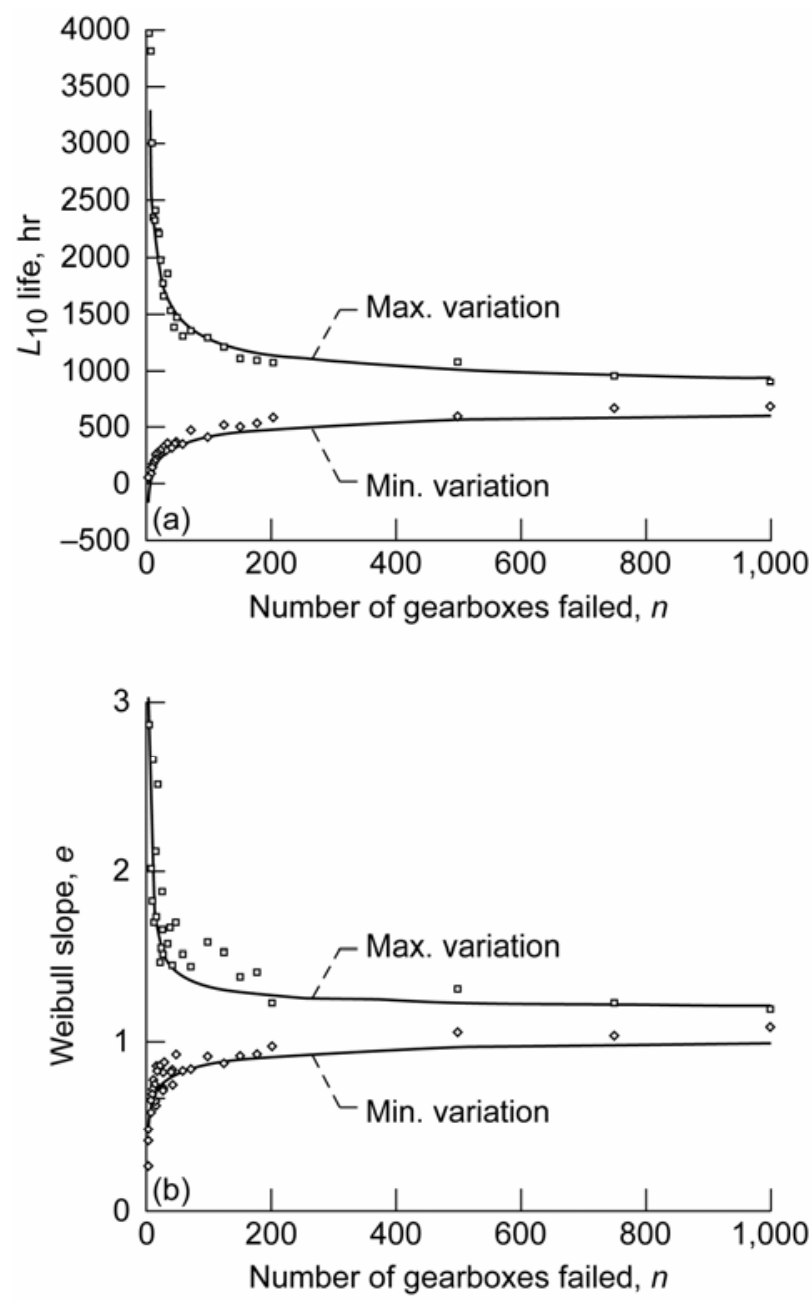

Figure 4.-Average values of maximum and minimum variations of life and Weibull slope from Monte Carlo simulation of assembly and testing of $744,450 \mathrm{com}-$ mercial turboprop gearboxes as a function of number of gearboxes failed. (a) $L_{10}$ life. (b) Weibull slope. 
The variation in life is a function of the number of gearboxes failed and not the number of gearboxes tested or in the field (ref. 28). The equations providing a reasonable bounding fit of these data (fig. 4) are as follows:

$$
\begin{gathered}
\text { Maximum } L_{10} \text { life }=\left(\text { median or predicted } L_{10} \text { life }\right)\left(1+6.5 n^{-0.5}\right) \\
\text { Minimum } L_{10} \text { life }=\left(\text { median or predicted } L_{10} \text { life }\right)\left(1.0-1.85 n^{-0.3}\right) \\
\text { Minimum } L_{10} \text { life } \rightarrow 0 \text { where } n \leq 3
\end{gathered}
$$

The maximum and minimum Weibull slopes of 21 trials were also averaged for 10 repetitions and plotted as a function of population size in figure 4(b). The variations in Weibull slope as a function of the number of gearboxes failed are as follows:

$$
\begin{aligned}
& \text { Maximum Weibull slope }=1.125+[5.0(\ln n)]^{-0.5} \\
& \text { Minimum Weibull slope }=1.125-(1.125 n)^{-0.3}
\end{aligned}
$$

There is good correlation between the median values of the Weibull slopes from the Monte Carlo simulation and that predicted for the gearboxes based on the Weibull slope of the lowest lived component

\begin{tabular}{|c|c|c|c|}
\hline \multicolumn{4}{|c|}{$\begin{array}{c}\text { TABLE 3.-SUMMARY OF LIVES FROM FIELD DA7 } \\
\text { OF NEW AND REFURBISHED COMMERCIAL } \\
\text { TURBOPROP GEARBOXES COMPARED WITH } \\
\text { PREDICTED LIVES USING LUNBERG- } \\
\text { PALMGREN LIFE THEORY }\end{array}$} \\
\hline \multirow[t]{2}{*}{ Life, hr } & \multicolumn{2}{|c|}{$\begin{array}{c}\text { Field failure data gearbox } \\
\text { designation }\end{array}$} & \multirow[t]{2}{*}{$\begin{array}{c}\text { Predicted } \\
\text { (table 1) }\end{array}$} \\
\hline & New & Refurbished & \\
\hline$L_{10}$ & 5,627 & 1,334 & 774 \\
\hline$L_{50}$ & 13,303 & 5,597 & 4,132 \\
\hline Characteristic, $L_{\beta}$ & 15,727 & 7,398 & 5,721 \\
\hline Mean & ${ }^{\mathrm{a}} 13,928$ & b6,819 & ${ }^{\mathrm{c}} 5,481$ \\
\hline Weibull slope, $e$ & 2.189 & 1.313 & 1.125 \\
\hline
\end{tabular}
in the gearbox itself, particularly for trial populations greater than 58 (table 3). However, half the resultant Weibull slopes will be greater than that predicted and the other half less. Again, the magnitude of the Weibull slope variation depends on the number of gearboxes that fail in a set and not the number in a set (refs. 19 and 28).

The work reported herein shows that gearbox or drive train failure is probabilistic and not deterministic. The specific life of individual drive trains cannot be determined with any reasonable engineering certainty. Further, the remaining life of a drive train in service cannot be determined prior to actual failure of a component within the gearbox. Assuming an ideal and accurate gearbox life prediction procedure, half of all gearbox groups from carefully controlled assemblies will have lives less than that predicted. However, the variation in the resultant life from that predicted will decrease as the number of failed gearboxes in the randomly selected group increases. 


\section{Gearbox Field Data}

\section{New gearboxes}

The application of the Lundberg-Palmgren theory (ref. 5) to predict gearbox life and reliability needs to be benchmarked and verified under a varied load and operating profile. The cost and time to laboratory test a statistically significant number of gearboxes to determine their life and reliability is prohibitive. A practical solution to this problem is to benchmark the analysis to field data. Fortunately, these data were available for the commercial turboprop gearbox used in this study.

No two gearboxes are expected to operate in exactly the same manner. Flight variables include operating temperature and load. Small variations in operational load can result in significant changes in life. Hence, the accuracy of our calculations is dependent on how close the defined mission profile is to actual flight operation.

The gearboxes are condition monitored and are removed from service upon the detection of a perceived component failure. At the time of removal, the gearboxes are functional. The removal precludes secondary damage; that is, the damage is limited to the failed component.

Field data were collected for 64 new commercial turboprop gearboxes. From these field data, the resultant time to removal of each gearbox is presented in the Weibull plot of figure 5(a). The failure index was 59 out of 64 . That is, 59 out of the 64 gearboxes removed from service were considered failed. For these data, there was not a breakdown of the cause for removal or the percent of each component that had failed. The resultant $L_{10}$ life from the field data was $5,627 \mathrm{hr}$ and the Weibull slope $e$ was 2.189. Using the Lundberg-Palmgren method (above), the predicted $L_{10}$ life was $774 \mathrm{hr}$ and the Weibull slope $e$ was 1.125. The field data suggest that the $L_{10}$ life of the gearbox was under predicted by a factor of 7.56.

\section{Refurbished gearboxes}

When a gearbox is removed for cause, the failed and/or damaged components are removed. The gearbox is refurbished and put back into service. The 59 failed gearboxes were refurbished and placed back into service. The lives of these second-run gearboxes are presented in the Weibull plot of figure 5(b). The failure index was 34 out of 59. The times shown are based on setting the clock back to zero when these gearboxes were placed back into service. The resultant $L_{10}$ life of these second-run gearboxes was 1,334 hr. The Weibull slope $e$ was 1.313 . A comparison of the predicted lives and the lives of the new and refurbished gearboxes is shown in figure 5(c). The $L_{10}$ life of the refurbished gearbox is approximately 1.7 times that originally predicted for new gearboxes but 76 percent less than that of the first-run (new) gearboxes.

\section{Reevaluation of Bearing Load-Life Exponent $p$}

Although errors in the assumed operating profile of the gearbox may account for the difference between actual and predicted life, it is suggested that using the Lundberg-Palmgren equations results in a life prediction that is too low for the bearings.

With reference to equation (1), in their 1952 publication (ref. 20), Lundberg and Palmgren proposed a load-life exponent $p=10 / 3$ for roller bearings, where one raceway has point contact and the other raceway has line contact. The 10/3 load-life exponent has been incorporated in the ANSI/ABMA/ISO standards first published in 1953 (refs. 11 to 13). Their assumption of point and line contact may have been correct for many types of roller bearings then in use. However, it is no longer the case for most roller bearings manufactured today, and most certainly not, for cylindrical roller bearings. The computer analysis employed for the bearing life calculations used a value of $p=3$ for ball bearings and $p=4$ for roller bearings. Poplawski, Peters, and Zaretsky (ref. 29) suggest the use of $p=4$ for ball bearings and $p=5$ for roller bearings. 

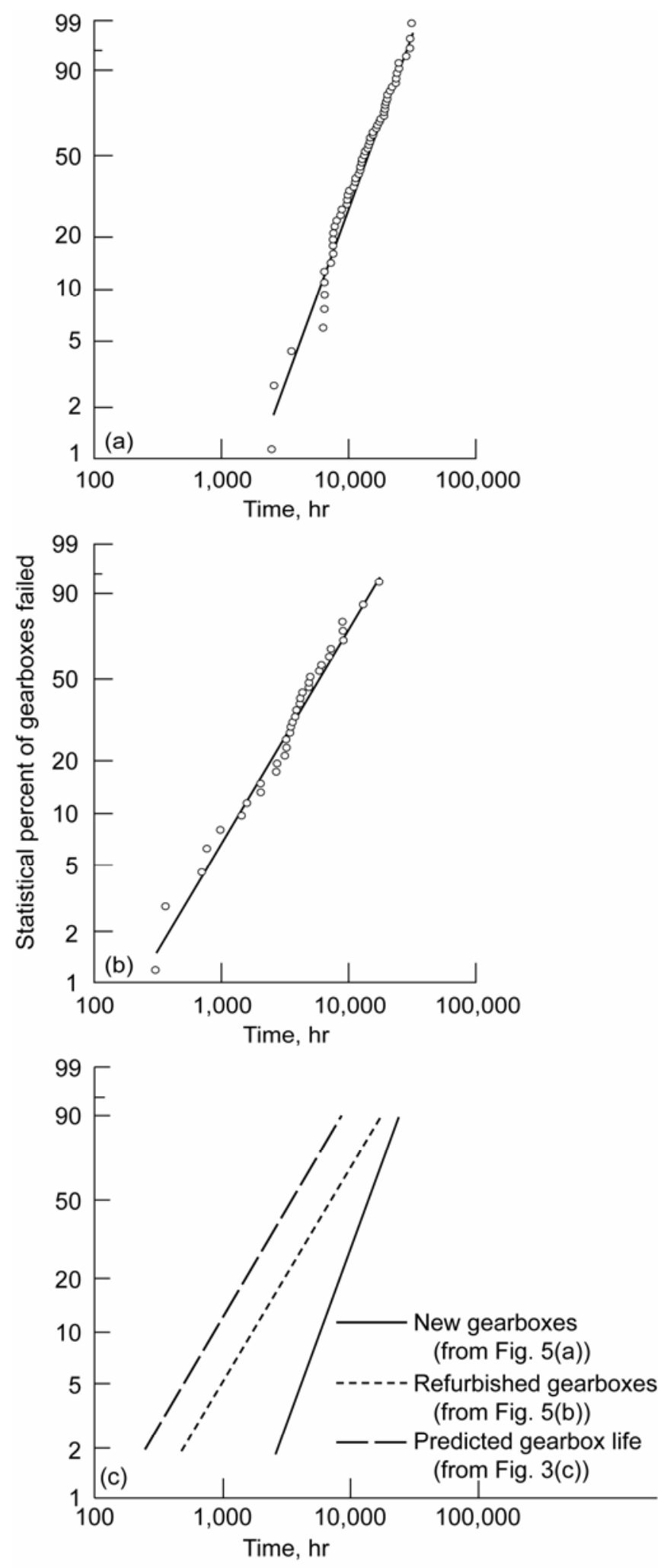

Figure 5.-Field data for lives of new and refurbished turboprop gearboxes compared with predicted lives using strict-series system reliability. (a) New gearbox lives.

(b) Refurbished gearbox lives. (c) Comparison of predicted lives and lives of new and refurbished gearboxes. 
From equation (11), assuming that the bearing system, which is the shortest lived component in the gear box and has the same Weibull slope as that of the gearbox (that is $e=2.189$ ),

$$
\frac{1}{L_{s y s}^{e_{s}}}=\frac{1}{L_{B}^{e_{B}}}+\frac{1}{L_{G}^{e_{G}}}
$$

and substituting in the known values

$$
\frac{1}{(5,627)^{2.189}}=\frac{1}{L_{B}^{2.189}}+\frac{1}{(16,680)^{2.5}}
$$

and solving for the bearing system life, results in a value of

$$
L_{B}=5,627 \mathrm{hr}
$$

From Lundberg-Palmgren (ref. 5), the predicted bearing system life is

$$
L_{B} \sim\left(\frac{C_{D}}{P_{e q}}\right)^{4} \sim 774 \mathrm{hr}
$$

then,

$$
\left(\frac{C_{D}}{P_{e q}}\right) \sim 5.27
$$

Calculating a revised value for the load-life exponent $p$ for the gearbox bearings based on the actual bearing system life of 5,627 hr,

$$
\left(\frac{C_{D}}{P_{e q}}\right)^{p} \sim(5.27)^{p} \sim 5,627 \mathrm{hr}
$$

Solving for load-life exponent $p$,

$$
p=5.2
$$

where according to Poplawski, Peters, and Zaretsky (ref. 30),

$$
4 \leq p \leq 5
$$

The apparent load-life exponent $p$ for the roller bearings is equal to 5.2. Were the roller bearing lives to be recalculated using the Lundberg-Palmgren theory with a load-life exponent $p=5.2$, the predicted $L_{10}$ life of the gearbox would be equal to the actual life obtained in the field, 5,627 hr. It should be noted that if an exponent $p=5$ were used, the predicted $L_{10}$ life of the gearbox would be $4,065 \mathrm{hr}$. This result suggests a strong reliance of the predicted bearing life upon the load-life exponent $p$. The values of the load-life exponent $p$ for roller bearings equal to 10/3 from the ANSI/ABMA and ISO standards (refs. 21 to 23) and 
4 from computer codes may provide predicted roller bearing lives that are too conservative for design purposes.

\section{Component Life}

With reference to equation (11), failure trends in the percentage of individual components failed with respect to the total system can be derived from the Lundberg-Palmgren model for system failure (ref. 5) and are expressed by Johnson (ref. 19) as follows:

$$
X=\frac{L_{\text {sys }}^{e}}{L_{n}^{e}}
$$

where $X$ is the fractional percent of components failed, $L_{\text {sys }}$ is the system $L_{10}$ life, and $L_{n}$ is the component $L_{10}$ life. If the percent of each component failed as a percentage of the total number of gearboxes failed is known, then the $L_{10}$ life of that component can be determined from equation (17) and vice versa. However, a condition precedent for using equation (17) is that the individual Weibull slopes must be known or assumed with reasonable engineering certainty.

Based on the Monte Carlo simulation, the component failure distribution of the gearbox for 744,450 gearboxes is summarized in table 4 . These numbers are compared with the calculated failure distribution predicted using the predicted component $L_{10}$ lives obtained using strict-series system reliability. These numbers are nearly identical and prove the comparability of these methods.

TABLE 4.-PREDICTED FAILURE DISTRIBUTION BASED ON MONTE CARLO STUDY AND STRICT-SERIES SYSTEM RELIABILITY

\begin{tabular}{|c|c|c|}
\hline \multirow{2}{*}{$\begin{array}{l}\text { Component description } \\
\text { (fig. 1) }\end{array}$} & \multicolumn{2}{|c|}{ Components failed, percent } \\
\hline & Monte Carlo study & $\begin{array}{l}\text { Strict-series system reliability } \\
\text { (From eq. (17) and table } 1 \text { ) }\end{array}$ \\
\hline \multicolumn{3}{|c|}{ Rolling-element bearings } \\
\hline \multicolumn{3}{|l|}{ Cylindrical roller bearings } \\
\hline Front pinion & 2.26 & 2.45 \\
\hline Rear pinion & 2.42 & 2.40 \\
\hline Main drive & 1.93 & 1.88 \\
\hline Carrier support & 0.11 & 0.12 \\
\hline Propeller radial & 0.64 & 0.65 \\
\hline Propeller thrust ball bearing & 1.45 & 1.71 \\
\hline Planet double-row spherical roller bearing set, 5 bearings & 89.46 & 90.72 \\
\hline \multicolumn{3}{|c|}{ Gears } \\
\hline Pinion & 0.11 & 0.00 \\
\hline Ring & 0.00 & 1 \\
\hline Sun & 1.21 & \\
\hline Main drive & 0.01 & \\
\hline Planet gear set, 5 gears & 0.42 & $\downarrow$ \\
\hline
\end{tabular}

On the basis of the predicted percentage of components failed from the Monte Carlo analysis and equation (17), the lives of the individual components are predicted based on the $L_{10}$ life of the new gearboxes in the field, where $L_{\text {sys }}=L_{10}=5,627 \mathrm{hr}$. For these calculations, the Weibull slope $e$ for all the components was assumed to be the same as the resultant Weibull slope of the gearboxes in the field, where $e=2.189$ (table 3 ). These lives are compared with those originally predicted for the components from table 1. Regarding the $L_{10}$ lives, although the differences between those predicted from equation (17) for the various components are within reasonable engineering limits, there are two exceptions: The $L_{10}$ life of the five-planet, double-row spherical roller set is over seven times that predicted. Also, the calculated $L_{10}$ life from equation (17) for the ring gear is 98.5 percent less than that predicted. However, the resultant ring gear life is sufficiently high enough to have only a nominal effect 
on the gearbox life. The increase in $L_{10}$ life of the five-planet, double-row spherical roller set is of sufficient magnitude to significantly increase the overall gearbox life from the predicted value of $774 \mathrm{hr}$ (table 1) to 5,627 hr (table 3).

\section{Summary of Results}

Two computational models to determine the fatigue life and reliability of a commercial turboprop gearbox are compared with each other and with field data. These models are (1) the Monte Carlo simulation of randomly selected lives of individual bearings and gears comprising the system and (2) the two-parameter Weibull distribution function for bearings and gears comprising the system using strictseries system reliability to combine the calculated individual component lives in the gearbox. The Monte Carlo simulation consisted of the virtual testing of 744,450 gearboxes. These results were compared with each other and with two sets of field data obtained from 64 gearboxes that were first-run to removal for cause, were refurbished, were placed back in service, and were second-run until removal for cause. A series of equations was empirically developed from the Monte Carlo simulation to determine the statistical variation in predicted life and Weibull slope as a function of the number of gearboxes failed. The following results were obtained:

1. The resultant $L_{10}$ life from the field data was $5,627 \mathrm{hr}$ and the Weibull slope $e$ was 2.189 . Using the Lundberg-Palmgren theory, the predicted $L_{10}$ life was $774 \mathrm{hr}$ and the Weibull slope $e$ was 1.125. The field data suggest that the life of the gearbox was under predicted by a factor of 7.56.

2. The resultant $L_{10}$ life of the second-run (refurbished) gearboxes was $1,334 \mathrm{hr}$. The Weibull slope $e$ was 1.313 . The $L_{10}$ life of the refurbished gearbox is approximately 1.7 times that originally predicted for new gearboxes but is 76 percent less than that of the first-run (new) gearboxes.

3. From the Monte Carlo simulation, the median values for the $L_{10}$ gearbox lives equal $757 \mathrm{hr}$ and reasonably correlate with the predicted value using strict-series system reliability of $774 \mathrm{hr}$. Half of the gearbox $L_{10}$ lives are less than this value and the other half more. The variation in the resultant life from that predicted decreases as the number of failed gearboxes in the randomly selected group increases.

4. The apparent load-life exponent $p$ for the roller bearings is equal to 5.2. Were the lives of the roller bearings to be recalculated using the Lundberg-Palmgren theory with a load-life exponent $p=5.2$, the predicted $L_{10}$ life of the gearbox would be equal to the actual life obtained in the field, $5,627 \mathrm{hr}$. If an exponent $p=5$ were used, the predicted $L_{10}$ life of the gearbox would be $4,065 \mathrm{hr}$. This result suggests a strong reliance of the predicted life upon the load-life exponent $p$.

5. The component failure distribution of the gearbox from the Monte Carlo simulation was nearly identical to that obtained by using the strict-series system reliability analysis, proving the comparability of these methods.

\section{References}

1. Zaretsky, E.V. (1992), "STLE Life Factors for Rolling Bearings," STLE SP-34, STLE, Park Ridge, IL.

2. Weibull, W. (1939), "A Statistical Theory of the Strength of Materials," Ingenioersvestenskapsakademiens. Handl., 151.

3. Weibull, W. (1939), "The Phenomenon of Rupture of Solids," Ingeniorsvetenkapsakademiens. Handl., 153.

4. Weibull, W. (1951), “A Statistical Distribution Function of Wide Applicability," J. Appl. Mech., Trans. ASME, 18, 3, pp. 293-297.

5. Lundberg, G., and Palmgren, A. (1947), "Dynamic Capacity of Rolling Bearings," A. Polytechn., 196. 
6. Coy, J.J., Townsend, D.P., and Zaretsky, E.V. (1976), "Dynamic Capacity and Surface Fatigue Life for Spur and Helical Gears,” J. Lubr. Technol., Trans. ASME, 98, 2, pp. 267-276.

7. Coy, J.J., Townsend, D.P., and Zaretsky, E.V. (1975), "Analysis of Dynamic Capacity of LowContact-Ratio Spur Gears Using Lundberg-Palmgren Theory," NASA TN D-8029, NASA, Cleveland, $\mathrm{OH}$.

8. Coy, J.J., and Zaretsky, E.V. (1975), "Life Analysis of Helical Gear Sets Using Lundberg-Palmgren Theory," NASA TN D-8045, NASA, Cleveland, OH.

9. Coy, J.J., Townsend, D.P., and Zaretsky, E.V. (1983), “An Update on the Life Analysis of Spur Gears," in Advanced Power Transmission Technology, NASA, Cleveland, OH, NASA CP-2210, pp. 421-434.

10. Savage, M., Knorr, R.J., and Coy, J.J. (1982), "Life and Reliability Models for Helicopter Transmissions,” NASA TM-82976 (AHS-RWP-16), NASA, Cleveland, OH.

11. Savage, M., Paridon, C.A., and Coy, J.J. (1983), "Reliability Model for Planetary Gear Trains," J. Mech. Transm. Autom. Des., 105, 3, pp. 291-297.

12. Savage, M., Brikmanis, C., Lewicki, D.G., and Coy, J.J. (1988), "Life and Reliability Modeling of Bevel Gear Reductions," J. Mech. Transm. Autom. Des., Trans. ASME, 110, 2, pp. 189-196.

13. Savage, M., Radil, K.C., Lewicki, D.G., and Coy, J.J. (1989), "Computerized Life and Reliability Modeling for Turboprop Transmissions," J. Propul. P., Trans. AIAA, 5, 5, pp. 610-614.

14. Savage, M. (1990), "Drive System Life and Reliability," in Rotorcraft Drivetrain Life, Safety and Reliability, AGARD, Neuilly-Sur-Seine, France, AGARD-R-775, pp. 35-71.

15. Savage, M. (1991), "Life and Dynamic Capacity Modeling for Aircraft Transmissions; Final Report" NASA CR-4341 (AVSCOM-TR-90-C-027), NASA, Cleveland, OH.

16. Lewicki, D.G., Black, J.D., Savage, M., and Coy, J.J. (1986), "Fatigue Life Analysis of a Turboprop Reduction Gearbox,” J. Mech. Trans. Autom. Des, Trans. ASME, 108, 2, pp. 255-262.

17. Mooney, C.Z. (1997), Monte Carlo Simulation, Sage Publications, Thousand Oaks, CA, 6.

18. Vlcek, B.L., Hendricks, R.C., and Zaretsky, E.V. (2003), "Determination of Rolling-Element Fatigue Life From Computer Generated Bearing Tests,” Trib. Trans., 46, 4, pp. 479-493.

19. Johnson, L.G. (1964), The Statistical Treatment of Fatigue Experiments, Elsevier Publishing Co., Amsterdam.

20. Lundberg, G., and Palmgren, A. (1951), "Dynamic Capacity of Roller Bearings," A. Polytechn., $2,4$.

21. (1990), "Rolling Bearings_-Dynamic Load Ratings and Rating Life, First Edition," ISO281, International Organization for Standards, Geneva.

22. (1990), "Load Ratings and Fatigue Life for Ball Bearings," ANSI/AFBMA-9, American Bearing Manufacturers Association, Washington, DC.

23. (1990), "Load Ratings and Fatigue Life for Roller Bearings," ANSI/AFBMA-11, American Bearing Manufacturers Association, Washington, DC.

24. Townsend, D.P., Coy, J.J., and Zaretsky, E.V. (1978), "Experimental and Analytical Load-Life Relation for AISI 9310 Steel Spur Gears," J. Mech. Des., Trans. ASME, 100, 1, pp. 54-60.

25. Palmgren, A. (1924), "The Service Life of Ball Bearings," NASA TT-F-13460, Translation from Z. Ver. Dtsch. Ing., 68, 14, pp. 339-341.

26. Langer, B.F. (1937), "Fatigue Failure From Stress Cycles of Varying Amplitude,” J. App. Mech., Trans. ASME, 4, 4, pp. A160-A162.

27. Miner, M.A. (1945), “Cumulative Damage in Fatigue,” J. Appl. Mech., Trans. ASME, 12, 3, pp. A159-A164.

28. Vlcek, B. L., Hendricks, R.C., and Zaretsky, E. V. (2004), "Monte Carlo Simulation of Sudden Death Bearing Testing," Trib. Trans., 47, 2, pp.188-199.

29. Poplawski, J.V., Peters, S.M., and Zaretsky, E.V. (2001), "Effect of Roller Profile on Cylindrical Roller Bearing Life Prediction-Part I: Comparison of Bearing Life Theories," Trib. Trans., 44, 3, pp. 339-350. 


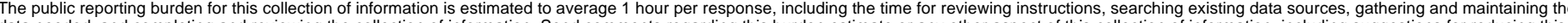

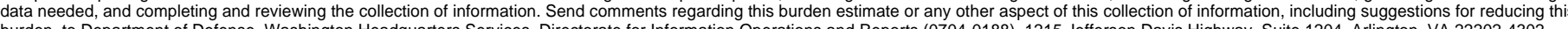
burden, to Department of Defense, Washington Headquarters Services, Directorate for Information Operations and Reports (0704-0188), 1215 Jefferson Davis Highway, Suite 1204, Arlington, VA 22202-4302.

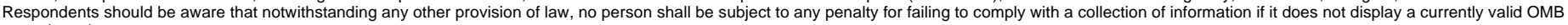
control number.

PLEASE DO NOT RETURN YOUR FORM TO THE ABOVE ADDRESS.

\begin{tabular}{|l|l|l}
\hline $\begin{array}{l}\text { 1. REPORT DATE (DD-MM-YYYY) } \\
01-11-2007\end{array}$ & $\begin{array}{l}\text { 2. REPORT TYPE } \\
\text { Technical Memorandum }\end{array}$ & 3. DATES COVERED (From - To) \\
\hline
\end{tabular}

\section{TITLE AND SUBTITLE}

Determination of Turboprop Reduction Gearbox System Fatigue Life and Reliability

5a. CONTRACT NUMBER

6. AUTHOR(S)

Zaretsky, Erwin, V.; Lewicki, David, G.; Savage, Michael; Vlcek, Brian, L.

b. GRANT NUMBER

5c. PROGRAM ELEMENT NUMBER

5d. PROJECT NUMBER

5e. TASK NUMBER

5f. WORK UNIT NUMBER

WBS 561581.02.07.03

\section{PERFORMING ORGANIZATION NAME(S) AND ADDRESS(ES)}

National Aeronautics and Space Administration

John H. Glenn Research Center at Lewis Field

8. PERFORMING ORGANIZATION REPORT NUMBER

Cleveland, Ohio 44135-3191

E-15467-1

\section{SPONSORING/MONITORING AGENCY NAME(S) AND ADDRESS(ES)}

National Aeronautics and Space Administration

Washington, DC 20546-0001

\section{SPONSORING/MONITORS ACRONYM(S) \\ NASA}

11. SPONSORING/MONITORING
REPORT NUMBER
NASA/TM-2007-215019

\section{DISTRIBUTIONIAVAILABILITY STATEMENT}

Unclassified-Unlimited

Subject Categories: 01, 05, 37, and 39

Available electronically at http://gltrs.grc.nasa.gov

This publication is available from the NASA Center for AeroSpace Information, 301-621-0390

\section{SUPPLEMENTARY NOTES}

\section{ABSTRACT}

Two computational models to determine the fatigue life and reliability of a commercial turboprop gearbox are compared with each other and with field data. These models are (1) Monte Carlo simulation of randomly selected lives of individual bearings and gears comprising the system and (2) two-parameter Weibull distribution function for bearings and gears comprising the system using strict-series system reliability to combine the calculated individual component lives in the gearbox. The Monte Carlo simulation included the virtual testing of 744,450 gearboxes. Two sets of field data were obtained from 64 gearboxes that were first-run to removal for cause, were refurbished and placed back in service, and then were second-run until removal for cause. A series of equations were empirically developed from the Monte Carlo simulation to determine the statistical variation in predicted life and Weibull slope as a function of the number of gearboxes failed. The resultant $L_{10}$ life from the field data was 5,627 hr. From strict-series system reliability, the predicted $L_{10}$ life was $774 \mathrm{hr}$. From the Monte Carlo simulation, the median value for the $L_{10}$ gearbox lives equaled $757 \mathrm{hr}$. Half of the gearbox $L_{10}$ lives will be less than this value and the other half more. The resultant $L_{10}$ life of the second-run (refurbished) gearboxes was 1,334 hr. The apparent load-life exponent $p$ for the roller bearings is 5.2. Were the bearing lives to be recalculated with a load-life exponent $p$ equal to 5.2 , the predicted $L_{10}$ life of the gearbox would be equal to the actual life obtained in the field. The component failure distribution of the gearbox from the Monte Carlo simulation was nearly identical to that using the strict-series system reliability analysis, proving the compatibility of these methods. 15. SUBJECT TERMS

Reliability; Life prediction-bearings; Gears; Gearbox; Probabilistic life prediction; Rolling-element bearings; Turboprop gearbox

\begin{tabular}{|c|c|c|c|c|}
\hline \multicolumn{3}{|c|}{ 16. SECURITY CLASSIFICATION OF: } & \multirow{2}{*}{$\begin{array}{l}\text { 17. LIMITATION OF } \\
\text { ABSTRACT } \\
\text { UU }\end{array}$} & \multirow{2}{*}{$\begin{array}{l}\text { 18. NUMBER } \\
\text { OF } \\
\text { PAGES } \\
24\end{array}$} \\
\hline $\begin{array}{l}\text { a. REPORT } \\
U\end{array}$ & $\begin{array}{l}\text { b. ABSTRACT } \\
\mathrm{U}\end{array}$ & $\begin{array}{l}\text { c. THIS } \\
\text { PAGE } \\
\text { U }\end{array}$ & & \\
\hline
\end{tabular}

19a. NAME OF RESPONSIBLE PERSON STI Help Desk (email:help@sti.nasa.gov) 19b. TELEPHONE NUMBER (include area code) 301-621-0390 

